\title{
Impairment of host defence by exotoxin $A$ in Pseudomonas aeruginosa pneumonia in mice
}

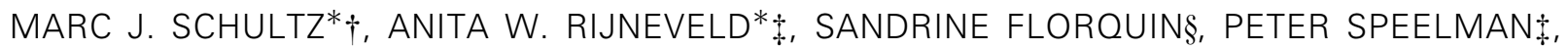 \\ SANDER J.H. VAN DEVENTER* and TOM VAN DER POLL** \\ * Laboratory of Experimental Internal Medicine, †Department of Intensive Care Medicine, \$Department of \\ Infectious Diseases, Tropical Medicine and AIDS and §Department of Pathology, Academic Medical Center, \\ University of Amsterdam, Amsterdam, The Netherlands
}

\begin{abstract}
Exotoxin A (P-ExA) is considered to be a major virulence factor of Pseudomonas aeruginosa. Neutrophils, cytokines and nitric oxide (NO) have been implicated as important components of an effective host defence against bacterial respiratory tract infection. To study the role of P-ExA in the pathogenesis of $P$. aeruginosa pneumonia, C57Bl/6 mice were inoculated intranasally with wild-type PA103 or a mutant $P$. aeruginosa strain that did not produce P-ExA, PA103-29. P-ExA facilitated the outgrowth of $P$. aeruginosa in lungs, as reflected by an increasing number of cfu during pneumonia with strain PA103, whereas the number of cfu decreased during pulmonary infection with strain PA103-29. Influx of neutrophils was similar in broncho-alveolar lavage fluids (BALF) during pneumonia with strains PA103 and PA103-29. Lung levels of cytokines (tumor necrosis factor-alpha, interleukin-6) and chemokines (macrophage inflammatory protein-2, KC) were higher in mice inoculated with strain PA103, whereas BALF concentrations of NO were similar in mice treated with strains PA103 and PA10329. These data suggest that P-ExA impairs host defence during pneumonia caused by $P$. aeruginosa by a mechanism that does not involve effects on neutrophil influx, cytokines, chemokines or NO formation.
\end{abstract}

\section{Introduction}

Pseudomonas aeruginosa is the most frequent gramnegative pathogen causing nosocomial pneumonia $[1,2]$. Ventilator-associated pneumonia caused by $P$. aeruginosa has a mortality rate of $40-68 \%$ and treatment with antibiotics does not improve survival $[3,4]$. Moreover, treatment is hampered by increasing resistance against antibiotics. A growing line of evidence suggests that $P$. aeruginosa exotoxin A (PExA) is a major virulence factor involved in pseudomonal infections. The toxicity of this single-chain 66$\mathrm{kDa}$ polypeptide is due to its ability to inhibit protein synthesis after translocation to the cytosol of susceptible cells [5]. Mortality in mice challenged with an intraperitoneal injection of P-ExA-producing $P$. aeruginosa is higher than in mice challenged with P-ExAdeficient mutant bacteria, and anti-P-ExA monoclonal antibodies exert a protective effect during $P$. aerugino-

Received 31 July 2000; revised version received 20 March 2001; accepted 21 March 2001.

Corresponding author: Dr M.J. Schultz (e-mail: m.j.schultz@ uva.amc.nl). $s a$ infection in mice $[6,7]$. A single injection of P-ExA alone significantly reduces the number of neutrophils in peripheral blood, suggesting a direct effect of P-ExA on neutrophils [7].

Immune host defence plays an important role in the outcome of bacterial pneumonia. Alveolar macrophages release various mediators upon invasion of pathogens, including cytokines and chemokines, leading to a vigorous inflammatory response, involving the recruitment of neutrophils and the production of nitric oxide (NO). Local production of pro-inflammatory cytokines makes an important contribution to host defence against pneumonia with pathogens like Streptococcus pneumoniae [8-10], Klebsiella pneumoniae [11-13] and P. aeruginosa [14-16].

The present study investigated the different elements involved in host defence during $P$. aeruginosa pneumonia, and the influence of P-ExA. Therefore, it compared bacterial outgrowth, the local production of cytokines and chemokines, neutrophil recruitment and NO production in a mouse model of respiratory tract infection with either wild-type $P$. aeruginosa or a 
hypotoxigenetic $P$. aeruginosa mutant strain, with a chemically derived mutation in $\operatorname{reg} A$, that did not produce P-ExA [17].

\section{Materials and methods}

\section{Animals}

Female C57B1/6 mice (8-10 weeks) (Harlan, Horst, The Netherlands) were used in all experiments. The protocol was approved by the Institutional Animal Care and Use Committee of the Academic Medical Center.

\section{Induction of pneumonia}

Strains PA103 and PA103-29, provided by Dr B. Iglewski (Iglewski Laboratory, Rochester, NY, USA), were grown to mid-logarithmic phase in Luria broth for $6 \mathrm{~h}$ at $37^{\circ} \mathrm{C}$, harvested by centrifugation at $1500 \mathrm{~g}$ for $15 \mathrm{~min}$, washed twice in pyrogen-free $\mathrm{NaCl} 0.9 \%$ and resuspended in $10 \mathrm{ml}$ of $\mathrm{NaCl} 0.9 \%$ The number of bacteria was determined by serial dilution in sterile isotonic saline and culture on blood agar plates for $16 \mathrm{~h}$. Mice were lightly anaesthetised with inhaled isoflurane (Forene ${ }^{\circledR}$; Abott, Queensborough, Kent) and an inoculum of $50 \mu \mathrm{l}$ of the solution was administered intranasally. Some mice were inoculated with $50 \mu \mathrm{l}$ of sterile $\mathrm{NaCl} 0.9 \%$ alone (control mice).

\section{Preparation of lung homogenates}

At 6 and $24 \mathrm{~h}$ after inoculation, mice were anaesthetised with Hypnorm ${ }^{\circledR}$ (Janssen Pharmaceutica, Beerse, Belgium) and midazolam (Roche, Mijdrecht, The Netherlands) and blood was collected from the inferior vena cava in heparin-containing vacutainer tubes. Whole lungs were harvested and homogenised at $4^{\circ} \mathrm{C}$ in 5 volumes of sterile $\mathrm{NaCl} 0.9 \%$ in a tissue homogeniser that was carefully cleaned and disinfected with alcohol $70 \%$ after each homogenisation. Serial 10 -fold dilutions in sterile isotonic saline were made of these homogenates (and blood), and 50- $\mu 1$ volumes were plated on to sheep blood agar plates and incubated at $37^{\circ} \mathrm{C}$ in air with $\mathrm{CO}_{2} 5 \%$; cfu were counted after $24 \mathrm{~h}$. For cytokine measurements, lung homogenates were centrifuged at $1500 \mathrm{~g}$ for $15 \mathrm{~min}$ at $4^{\circ} \mathrm{C}$, supernates were filtered through a $35-\mu \mathrm{m}$ filter (Becton Dickinson, Lincoln Park, NJ, USA) and frozen at $-20^{\circ} \mathrm{C}$ until cytokine measurement.

\section{Broncho-alveolar lavage}

The trachea was exposed through a mid-line incision and cannulated with a sterile 22-gauge Abbocath-T catheter (Abbott, Sligo, Ireland). Broncho-alveolar lavage (BAL) was performed by instilling two $0.5-\mathrm{ml}$ volumes of isotonic saline; $0.9-1 \mathrm{ml}$ of BAL fluid (BALF) was retrieved per mouse, and total cell numbers and differential cell counts were determined from cytospins of each sample. BALF differential cell counts were done on cytospin preparations stained with modified Giemsa stain (Diff-Quick; Baxter, McGraw Park, IL, USA). BALF was then centrifuged at $750 \mathrm{~g}$ for $5 \mathrm{~min}$ at $4^{\circ} \mathrm{C}$ and supernates were frozen at $-20^{\circ} \mathrm{C}$ until measurements were performed.

\section{Histological examination}

For histopathological examination, lungs were fixed in buffered formalin $10 \%$ and embedded in paraffin; $4-\mu \mathrm{m}$ sections were stained with haematoxylin and eosin.

\section{Assays}

Cytokine and chemokine levels were measured by ELISAs according to the manufacturer's recommendations: tumor necrosis factor-alpha (TNF- $\alpha$; Genzyme, Cambridge, MA, USA), interleukin-6 (IL-6; Pharmingen), macrophage inflammatory protein-2 (MIP-2; R\&D Systems, Minneapolis, MN, USA) and KC ( $\mathrm{R} \& \mathrm{D}$ systems). $\mathrm{NO}_{2}{ }^{-} \mathrm{NO}_{3}{ }^{-}$concentrations in BALF were determined with a commercially available NO assay, according to the manufacturer's recommendations (R\&D Systems).

\section{Statistical analysis}

Comparisons of survival data were made by the logrank test. All other data are expressed as means and SEM. Comparisons between means were made by the Wilcoxon test. Significance was set at $p \leqslant 0.05$.

\section{Results}

Survival

Intranasal inoculation with either strain PA103 or strain PA103-29 led to a dose-dependent mortality (Fig. 1). While inoculation with $10^{4} \mathrm{cfu}$ did not cause death, mortality rates increased to $40 \%$ and $80 \%$ after administration of $10^{5}$ and $10^{6} \mathrm{cfu}$, respectively. Although mortality tended to be lower after inoculation with strain PA103-29, differences from strain PA103 did not reach statistical significance (Fig. 1). Further experiments comparing host responses to pulmonary infection with strains PA103 and PA103-29 were performed with a bacterial inoculum of $10^{5} \mathrm{cfu}$.

\section{Histology}

Inoculation with strains PA103 and PA103-29 induced signs of pneumonia in all mice. At $24 \mathrm{~h}$ after inoculation, lungs of mice displayed perivascular inflammatory infiltrates with endothelialitis. A slight interstitial infiltrate was also present (Fig. 2). At this time point there were no differences in the intensity and composition of the inflammation between mice inoculated with strain PA103 and mice inoculated with strain PA103-29. 
a

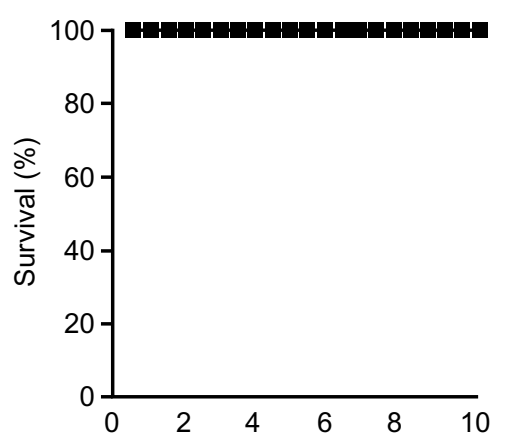

b

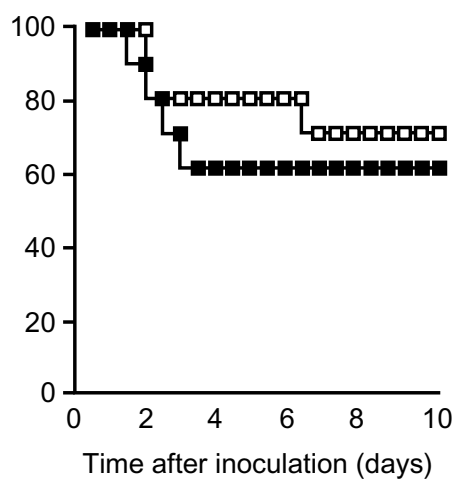

C

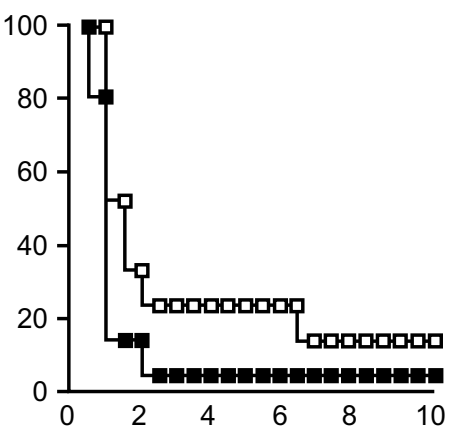

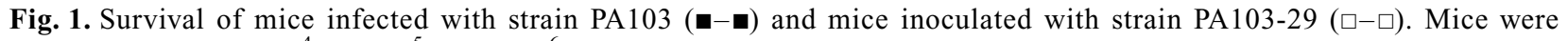
challenged with (a) $10^{4}$, (b) $10^{5}$ or (c) $10^{6} \mathrm{cfu}$ of $P$. aeruginosa; $\mathrm{n}=10$ mice group for each dose. Differences were not statistically significant.

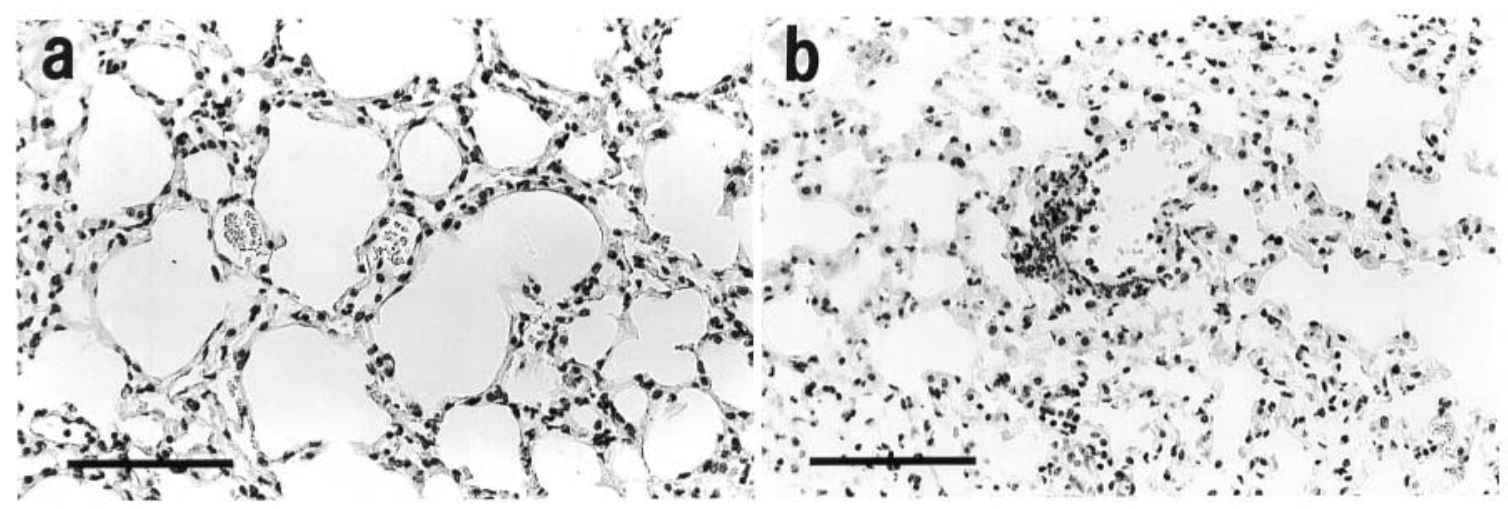

Fig. 2. Histopathology of lungs. Representative lung pathology $24 \mathrm{~h}$ after inoculation with either strain PA103 or strain PA103-29 (b) showing perivascular inflammation and slight interstitial inflammatory infiltrates compared with normal lung histology (a). Haematoxylin and eosin staining $(\mathrm{bar}=1 \mathrm{~mm})$. Sections are representative for the groups; $\mathrm{n}=5$ per group.

\section{Bacterial clearance}

As the importance of early events after induction of $P$. aeruginosa pneumonia was underscored in the survival curves, the study compared outgrowth of strains PA103 and PA103-29 in lungs at 6 and $24 \mathrm{~h}$ after inoculation (Fig. 3). After $6 \mathrm{~h}$ the number of cfu recovered from lungs was similar in mice challenged with strain PA103 or strain PA103-29, and none of the animals was bacteraemic. From 6 to $24 \mathrm{~h}$ after induction of pneumonia, strain PA103, but not strain PA103-29, demonstrated an increase in the number of cfu in lungs $(\mathrm{p}<0.05)$ After $24 \mathrm{~h}$ mice inoculated with strain PA103 had $>1 \log _{10}$ more cfu in lungs than mice inoculated with strain PA103-29 $(\mathrm{p}<0.05)$, while the number of cfu recovered from blood was similar -5.0 $(\mathrm{SEM} 2.7) \times 10^{2}$ and $2.9(\mathrm{SEM} 2.1) \times 10^{2} \mathrm{cfu} / \mathrm{ml}$ blood; NS.

\section{Neutrophil influx}

There was no difference in neutrophil influx in lungs in mice inoculated with either strain PA103 or strain PA103-29 (6 h after inoculation: 4.9 SEM $0.2 \times 10^{5} / \mathrm{ml}$

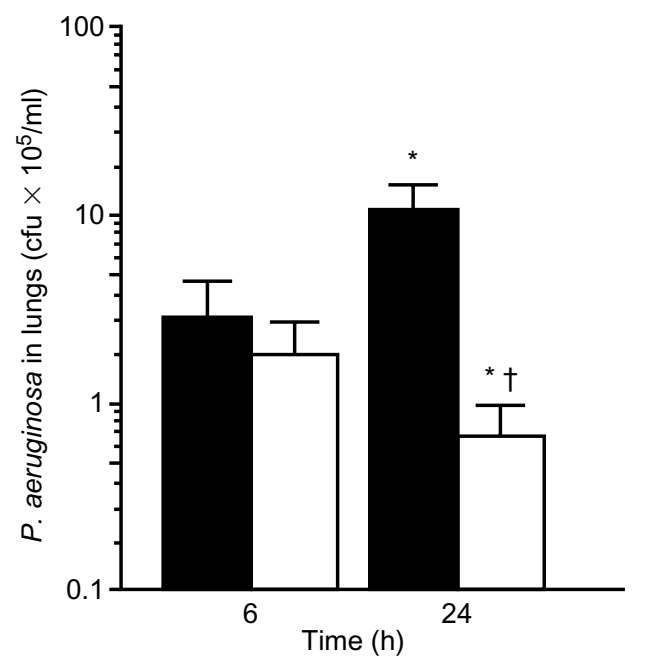

Fig. 3. Clearance of bacteria is enhanced in mice inoculated with strain PA103-29 compared with mice inoculated with strain PA103: mean (SEM) P. aeruginosa cfu in lungs 6 and $24 \mathrm{~h}$ after intranasal inoculation with $10^{5} \mathrm{cfu}$ of strain PA103 (-) and strain PA103-29 (口). $\mathrm{n}=8$ per time point for each bacterial strain. ${ }^{*} \mathrm{p}<0.05$ versus $6 \mathrm{~h}$ after inoculation, ${ }^{\dagger} \mathrm{p}<0.05$ versus strain PA103. 
versus $5.0 \mathrm{SEM} 0.4 \times 10^{5} / \mathrm{ml} ; 24 \mathrm{~h}$ after inoculation: 7.0 SEM $0.5 \times 10^{5} / \mathrm{ml}$ versus 6.8 SEM $0.9 \times 10^{5} / \mathrm{ml}$, NS), and no difference in the number of alveolar macrophages $(6 \mathrm{~h}$ after inoculation: 0.6 SEM $0.2 \times$ $10^{5} / \mathrm{ml}$ versus 0.3 SEM $0.1 \times 10^{5} / \mathrm{ml} ; 24 \mathrm{~h}$ after inoculation: $0.5 \mathrm{SEM} 0.1 \times 10^{5} / \mathrm{ml}$ versus $0.5 \mathrm{SEM}$ $\left.0.1 \times 10^{5} / \mathrm{ml}, \mathrm{NS}\right)$.

\section{Cytokines and chemokines}

Local production of cytokines and chemokines within the pulmonary compartment can influence host defence mechanisms in pneumonia $[8-14,18]$. Therefore, the concentrations of TNF- $\alpha$, IL-6, MIP-2 and KC in lung homogenates after inoculation with strains PA103 and PA103-29 were measured (Fig. 4). Pneumonia with either $P$. aeruginosa strain was associated with markedly elevated lung levels of each of these inflammatory mediators $(\mathrm{p}<0.05$ versus control). At $6 \mathrm{~h}$ after inoculation, cytokine and chemokine levels in lung homogenates of mice inoculated with strain PA103 or strain PA103-29 were similar. At $24 \mathrm{~h}$, TNF- $\alpha$, IL-6, MIP-2 and KC concentrations were higher in lungs of mice inoculated with strain PA103 than in mice inoculated with strain PA103-29 (all $\mathrm{p}<0.05)$.
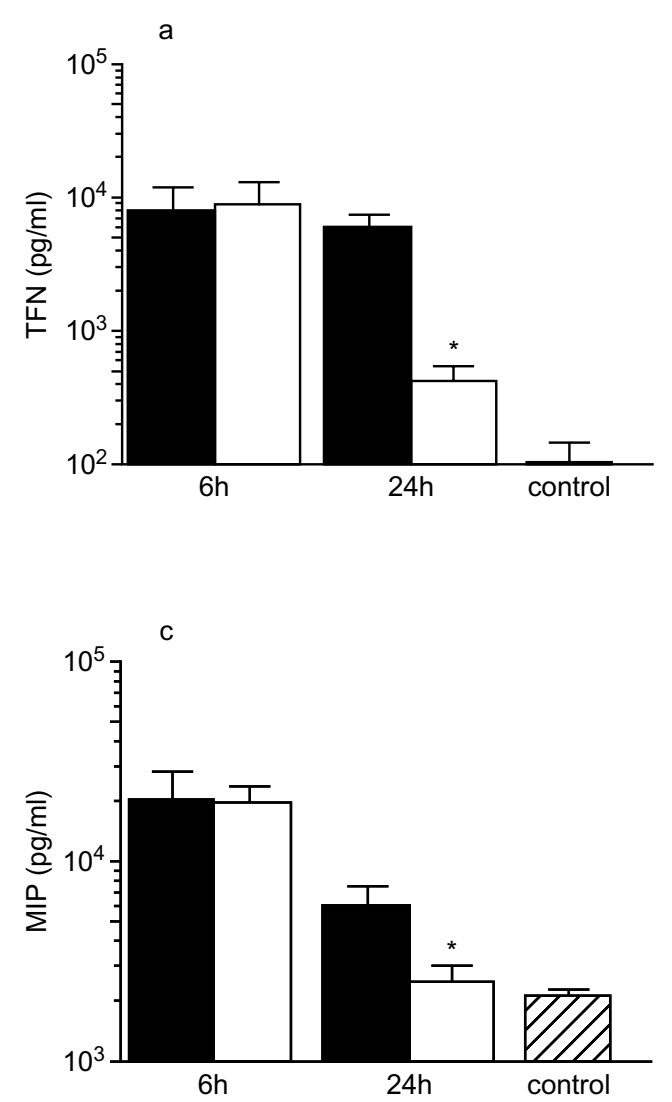

Nitric oxide

As the production of NO is important for host defence against pneumonia [19], the study compared NO levels in BALF after inoculation with strain PA103 or strain PA103-29 (Fig. 5). NO concentrations increased significantly during pneumonia with either bacterial strain ( $p<0.05$ versus control). Although, at $24 \mathrm{~h}, \mathrm{NO}$ levels tended to be higher in mice inoculated with strain PA103, the difference from strain PA103-29-treated animals did not reach statistical significance.

\section{Discussion}

P. aeruginosa induces a necrotising pneumonia and contributes to the morbidity and mortality of underlying diseases. P-ExA is considered to be a major virulence factor in pseudomonas infections. To determine the influence of P-ExA on different elements of host defence against pneumonia, the present study used a mouse model of respiratory tract infection with strains PA103 and PA103-29, two P. aeruginosa strains differing only in their ability to produce P-ExA. It was found that P-ExA facilitated the outgrowth of $P$. aeruginosa in lungs, as reflected by an increasing number of $P$. aeruginosa cfu during pneumonia with the wild-type strain PA103, whereas the number of $\mathrm{cfu}$
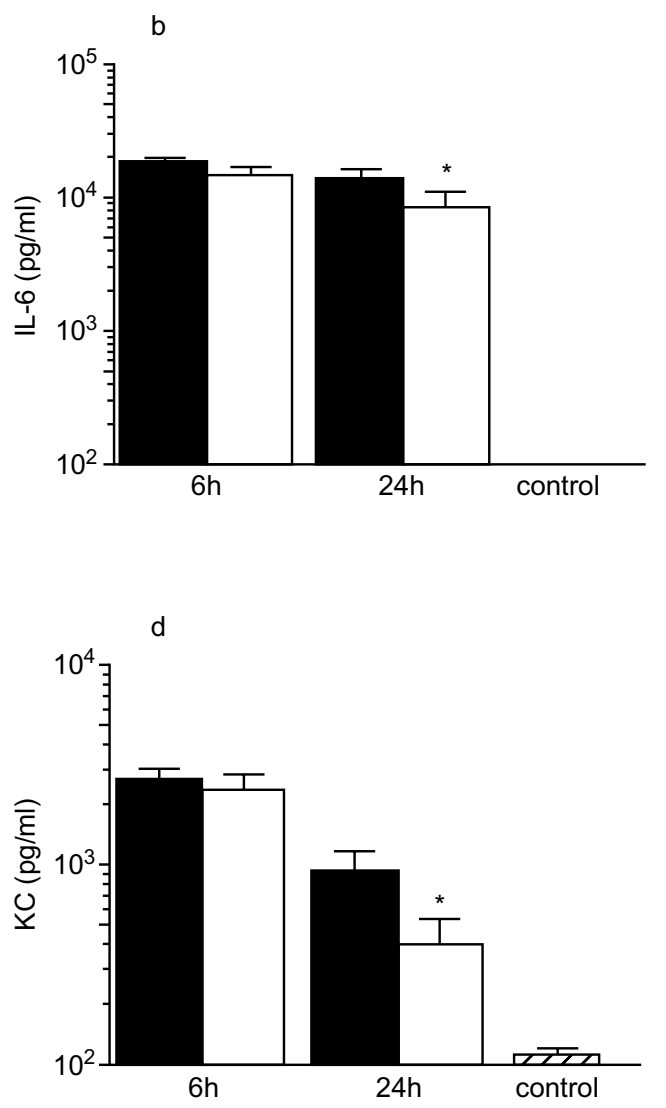

Fig. 4. Mean (SEM) cytokine and chemokine concentrations in lung in mice inoculated with strain PA103-29 () or strain PA103 (a). Control mice were inoculated with sterile saline and killed after $24 \mathrm{~h} . \mathrm{n}=8$ time point for each bacterial strain. ${ }^{*} \mathrm{p}<0.05$ versus strain PA103. 


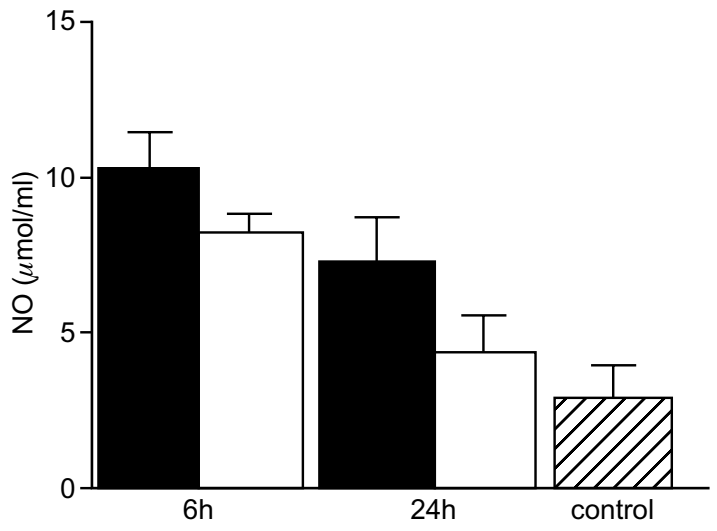

Fig. 5. Mean (SEM) NO concentrations in BALF of mice inoculated with strain PA103 (a) and strain PA103-29 $(\square)$. Control mice were inoculated with sterile saline and killed after $24 \mathrm{~h} . \mathrm{n}=8$ time point for each bacterial strain. Differences between mice inoculated with strains PA103 and PA103-29 were not statistically significant.

decreased during pulmonary infection with the P-ExAdeficient strain PA103-29.

Strain PA103-29 was derived from the parental PA103 strain by chemical mutagenesis [20]. Strain PA103-29 carries a mutation in the $\operatorname{reg} A$ gene, which results in a profoundly reduced ability to produce P-ExA [6, 20]. Quantitative assays, both enzymic and immunological, have indicated that strain PA103-29 produces P-ExA in vitro at levels of $\leqslant 0.3 \%$ of the parental strain PA103 levels [20]. Stability of $\operatorname{reg} A$ has been verified by invitro toxin assay $[6,21]$ and in-vivo experiments [7]. Several animal studies have shown that deficient production of P-ExA by strain PA103-29 is the major determinant of the difference in virulence between strains PA103 and PA103-29 [6, 7]. Thus, it is highly likely that the enhanced pulmonary clearance of strain PA103-29 in the present study was related to P-ExA deficiency rather than to other mutations that may influence the outcome of pneumonia.

Antibacterial host defence within the pulmonary compartment is regulated by a complex interplay between cellular and humoral effector mechanisms. The recruitment of neutrophils is essential for the clearance of bacteria when virulent bacteria enter the lower airspaces. The acute inflammatory response to invasion by $P$. aeruginosa consists of the emigration of neutrophils from pulmonary capillaries into the alveolar space. Importantly, this study did not find a difference in the extent of neutrophil influx in mice inoculated with strain PA103 or strain PA103-29, suggesting that the increased clearance of strain PA103-29 compared with strain PA103 was not the result of differences in the recruitment of neutrophils to the site of infection. Also, the density of alveolar macrophages, another cell population important in bacterial lung clearance [22], was not different in lungs from mice inoculated with strain PA103-29 or the wild-type $P$. aeruginosa strain. However, as the present study did not assess morphologic integrity and functionality of the neutrophils and alveolar macrophages, it remains possible that these cells are a target for cytotoxicity of P-ExA, eventually causing the differences found in the present study.

Inflammation during pneumonia is orchestrated by locally produced cytokines. The role of pro-inflammatory cytokines in pneumonia has been demonstrated in several experiments. Anti-TNF treatment has been found to hamper host defence mechanisms in mouse models of pneumococcal and klebsiella pneumonia $[9,13,23]$. Also, treatment of granulocytopenic mice with low doses of TNF significantly diminished mortality and enhanced pulmonary clearance of $P$. aeruginosa during severe pneumonia $[14,16]$. Evidence for the importance of IL-6 in host defence is derived from studies on pneumococcal pneumonia in IL-6deficient mice, demonstrating an increased bacterial outgrowth in lungs and enhanced mortality in these mice [8]. MIP-2 and $\mathrm{KC}$, cytokines with chemotactic activities, like TNF- $\alpha$ and IL- 6 seem to be important for resistance against respiratory tract infections. Treatment of mice with $K$. pneumoniae pneumonia with an anti-MIP-2 antibody caused a $60 \%$ decrease in lung neutrophil influx, a significant increase of outgrowth of bacteria from lungs and a decrease in early survival [11]. Similar results were found in a $P$. aeruginosa pneumonia model [22]. Finally, KC-transgenic mice with selective overexpression of $\mathrm{KC}$ in the lung showed increased bacterial clearance and improved survival, in association with enhanced influx of neutrophils to the lung, during $K$. pneumoniae pneumonia [24]. From these studies it can be concluded that endogenously produced TNF- $\alpha$, IL-6, MIP-2 and KC are important for host defence during pneumonia. Interestingly, P-ExA has been found to inhibit the production of 'protective' cytokines, including TNF- $\alpha$ and IL-6, in whole blood or peripheral blood mononuclear cells [25, 26]. Furthermore, P-ExA suppresses LPS-induced production by alveolar macrophages in vitro and dose-dependently reduced TNF- $\alpha$ release in BALF after intratracheal administration of lipopolysaccharide to mice in vivo [27]. Therefore, lower concentrations of TNF- $\alpha$ and IL- 6 were anticipated in lung homogenates of mice inoculated with strain PA103 than in lungs of mice treated with strain PA103-29, which might at least in part have explained the difference in clearance of bacteria from the lungs. However, the present study found higher concentrations of TNF- $\alpha$, IL-6, KC and MIP-2 in lungs of mice inoculated with strain PA103, compared with mice inoculated with strain PA103-29, at $24 \mathrm{~h}$ after inoculation. It is conceivable that cytokine levels in lung tissue are directly proportional to the number of bacteria present at that moment. Hence, a possible negative effect of P-ExA on cytokine production may have been masked by the higher number of strain PA103 cfu 
relative to the number of strain PA103-29 cfu recovered from lungs $24 \mathrm{~h}$ after the induction of pneumonia.

Although there was no significant difference in overall mortality between mice infected with strain PA103 and mice infected with strain PA103-29, the presence of P-ExA may have an impact on survival in infections in man. In this model, mice were challenged with bacteria only once, whereas in patients with cystic fibrosis, or mechanically ventilated patients, airways may be colonised with $P$. aeruginosa, leading to more chronic exposure to bacteria. Also, there are differences in the physiological state of the bacterial inoculum in this model compared with bacteria colonising patients during mechanical ventilation; in this model, washed bacteria in a logarithmic phase were used, whereas patients are exposed to aspiration of stationary phase, biofilm-grown bacteria. Furthermore, P-ExA may influence the host response against other pathogens present in the lungs at the same time in these patient groups. Studies in immunocompromised mice or mice with chronically infected airways or mixed pulmonary infections are needed to address the issue. The data from the present study are the first to suggest that P-ExA impairs host defence during respiratory tract infections by $P$. aeruginosa.

This work was supported by a grant from the Royal Dutch Academy of Arts and Sciences to T. van der P. We thank Dr B. Iglewski for providing $P$. aeruginosa strain 103-29.

\section{References}

1. Horan TC, White WJ, Jarvis WR et al. Nosocomial infection surveillance 1984. CDC MMWR Surveillance Summaries 1986; 35: 17SS-29SS.

2. Bodey GP, Bolivar R, Fainstein V, Jadeja L. Infections caused by Pseudomonas aeruginosa. Rev Infect Dis 1983; 5: 279-313.

3. Torres A, Aznar R, Gatell JM et al. Incidence, risk, and prognostic factors of nosocomial pneumonia in mechanically ventilated patients. Am Rev Respir Dis 1990; 142: 523-528.

4. Rouby JJ. Nosocomial infections in the critically ill: the lung as target organ. Anesthesiology 1996; 84: 757-759.

5. Iglewski BH, Kabat D. NAD-dependent inhibition of protein synthesis by Pseudomonas aeruginosa toxin. Proc Natl Acad Sci USA 1975; 72: 2284-2288.

6. Kohzuki T, Eguchi Y, Kato M et al. Protective activity of antiexotoxin A monoclonal antibody against mice infected with toxin-producing Pseudomonas aeruginosa. J Infect Dis 1993; 167: $119-125$

7. Miyazaki S, Matsumoto T, Tateda K, Ohno A, Yamaguchi K. Role of exotoxin A in inducing severe Pseudomonas aeruginosa infections in mice. J Med Microbiol 1995; 43: $169-175$.

8. van der Poll T, Keogh CV, Guirao X, Buurman WA, Kopf M, Lowry SF. Interleukin-6 gene-deficient mice show impaired defense against pneumococcal pneumonia. J Infect Dis 1997; 176: $439-444$

9. van der Poll T, Keogh CV, Buurman WA, Lowry SF. Passive immunization against tumor necrosis factor-alpha impairs host defense during pneumococcal pneumonia in mice. Am J Respir Crit Care Med 1997; 155: 603-608.

10. Rubins JB, Pomeroy C. Role of gamma interferon in the pathogenesis of bacteremic pneumococcal pneumonia. Infect Immun 1997; 65: 2975-2977.

11. Greenberger MJ, Strieter RM, Kunkel SL et al. Neutralization of macrophage inflammatory protein-2 attenuates neutrophil recruitment and bacterial clearance in murine Klebsiella pneumonia. J Infect Dis 1996; 173: 159-165.

12. Greenberger MJ, Kunkel SL, Strieter RM et al. IL-12 gene therapy protects mice in lethal Klebsiella pneumonia. $J$ Immunol 1996; 157: 3006-3012.

13. Laichalk LL, Kunkel SL, Strieter RM, Danforth JM, Bailie MB, Standiford TJ. Tumor necrosis factor mediates lung antibacterial host defense in murine Klebsiella pneumonia. Infect Immun 1996; 64: 5211-5218.

14. Amura C, Fontan PA, Sanjuan N, Sordelli DO. The effect of treatment with interleukin-1 and tumor necrosis factor on Pseudomonas aeruginosa lung infection in a granulocytopenic mouse model. Clin Immunol Immunopathol 1994; 73: $261-266$.

15. Kolls JK, Lei D, Nelson S, Summer WR, Greenberg S, Beutler B. Adenovirus-mediated blockade of tumor necrosis factor in mice protects against endotoxic shock yet impairs pulmonary host defense. J Infect Dis 1995; 171: 570-575.

16. Gosselin D, Desanctis J, Boulé M, Skamene E, Matouk C, Radzioch D. Role of tumor necrosis factor alpha in innate resistance to mouse pulmonary infection with Pseudomonas aeruginosa. Infect Immun 1995; 63: 3272-3278.

17. Hedstrom RC, Funk CR, Kaper JB, Pavlovskis OR, Galloway DR. Cloning of a gene involved in regulation of exotoxin A expression in Pseudomonas aeruginosa. Infect Immun 1986; 51: $37-42$.

18. van der Poll T, Marchant A, Keogh CV, Goldman M, Lowry SF. Interleukin-10 impairs host defense in murine pneumococcal pneumonia. J Infect Dis 1996; 174: 994-1000.

19. Tsai WC, Strieter RM, Zisman DA et al. Nitric oxide is required for effective innate immunity against Klebsiella pneumoniae. Infect Immun 1997; 65: 1870-1875.

20. Ohman DE, Sadoff JC, Iglewski BH. Toxin A-deficient mutants of Pseudomonas aeruginosa PA103: isolation and characterization. Infect Immun 1980; 28: 899-908.

21. Hirakata Y, Furuya N, Tateda K, Kaku M, Yamaguchi K. In vivo production of exotoxin $\mathrm{A}$ and its role in endogenous Pseudomonas aeruginosa septicemia in mice. Infect Immun 1993; 61: 2468-2473.

22. Kooguchi K, Hashimoto S, Kobayashi A et al. Role of alveolar macrophages in initiation and regulation of inflammation in Pseudomonas aeruginosa pneumonia. Infect Immun 1998; 66: 3164-3169.

23. Takashima K, Tateda K, Matsumoto T, Iizawa Y, Nakao M, Yamaguchi K. Role of tumor necrosis factor alpha in pathogenesis of pneumococcal pneumonia in mice. Infect Immun 1997; 65: 257-260.

24. Tsai WC, Strieter RM, Wilkowski JM et al. Lung-specific transgenic expression of $\mathrm{KC}$ enhances resistance to Klebsiella pneumoniae in mice. J Immunol 1998; 161: 2435-2440.

25. Schultz MJ, Speelman P, Zaat SAJ, Hack CE, Van Deventer $\mathrm{SJH}$, Van der Poll T. The effect of pseudomonas exotoxin A on cytokine production in whole blood exposed to Pseudomonas aeruginosa. FEMS Immunol Med Microbiol 2000; 29: 227-232.

26. Staugas RM, Harvey DP, Ferrante A, Nandoskar M, Allison AC. Induction of tumor necrosis factor (TNF) and interleukin-1 (IL-1) by Pseudomonas aeruginosa and exotoxin A-induced suppression of lymphoproliferation and TNF, lymphotoxin, gamma interferon, and IL-1 production in human leukocytes. Infect Immun 1992; 60: 3162-3168.

27. Hirakata Y, Kirikae T, Kirikae F et al. Effect of Pseudomonas aeruginosa exotoxin A on endotoxin-induced tumour necrosis factor production in murine lung. J Med Microbiol 1999; 48: $471-477$. 